\title{
Dialetheism in action: a new strategy for solving the equal validity paradox? Draft 1.3
}

\author{
Sebastiano Moruzzi and Annalisa Coliva
}

\begin{abstract}
This paper starts from the Equal Validity Paradox, a paradoxical argument connected to the so-called phenomenon of faultless disagreement. It is argued that there are at least six strategies for solving the paradox. After presenting the first five strategies and their main problems, the paper focuses on the sixth strategy which rejects the assumption that every proposition cannot be both true a false. Dialetheism is the natural candidate for developing strategy six. After presenting strategy six in detail, we formulate a normative problem for the dialetheist and offer a tentative solution to it. We then elaborate further considerations connecting strategy six to pluralism about truth and logic. Even if strategy six is a hard path to take, its scrutiny highlights some important points on truth, logic and the norms for acceptance and rejection. ${ }^{1}$
\end{abstract}

\footnotetext{
${ }^{1}$ This paper has been developed along a considerable amount of time. The general strategy of considering the prospects of dialetheism for making sense of relativism was first sketched in Coliva (2009); $\S 1-4.2$ have been elaborated jointly, while part of $\S 5$ and $\S \S 5.1-6$ have been developed by Sebastiano Moruzzi.
} 


\section{Contents}

1 Relativism and the Equal Validity Paradox 2

2 Six Ways Out of the Paradox 6

2.1 Strategy i: Revisionary Vs descriptive approaches . . . . . . . . 6

3 Semantic strategies $\quad 8$

3.1 Strategy (ii): the denial of Alethic Equal Validity - Realism, Contextualism and Relativism, Indeterminism . . . . . . . . . 8

3.2 Strategy (iii): the denial of Propositionality - Expressivism, Secondorder indeterminacy . . . . . . . . . . . . . . . . . 10

3.3 Strategy (iv): the denial of Incompatibility - Indexical Contextualism . . . . . . . . . . . . . . . . . . 12

4 Alethic Strategies $\quad 12$

4.1 Strategy (v): the denial of Utterance-Proposition Truth Schema 13

4.2 Strategy vi: the denial of LNC - Dialetheism . . . . . . . . . . . 14

5 The Normative Problem for Strategy (vi) 16

5.1 The epistemology of dialetheias . . . . . . . . . . . . . 23

6 Dialetheism, Trivialism and Pluralism 26

$\begin{array}{lll}7 & \text { Conclusions } & 31\end{array}$

\section{Relativism and the Equal Validity Para-} dox

A well known problem, perhaps the main difficulty, for any relativistic reading of the concept of faultless disagreement ${ }^{2}$ is that a genuine dispute seems

\footnotetext{
2The expression "faultless disagreement" has been introduced in the literature by Kölbel (2003). See Ferrari (2016a) for a useful normative analysis of the phenomenon.
} 
incompatible with the idea of equal validity - namely with the idea that the opinions involved in the dispute are equally valid. Suppose one party maintains that $p$ and another one that not- $p .^{3}$ The Law of Non-Contradiction (henceforth "LNC") tells us that they can't both be right (or wrong) hence relativism on faultless disagreement cannot be coherently formulated. Let's call this problem Equal Validity Paradox.

The present work intends to explore a strategy for blocking the Equal Validity Paradox that targets LNC. So, before proceeding it is important to be clear about the present interpretation of LNC. It is well known that there are several ways to formulate LNC, in fact several aspects have to be fixed in order to state this principle properly. First, it must determined the nature of the law: whether syntactic, pragmatic, semantic or metaphysical; secondly, it must be clarified the type of contradiction involved: whether explicit or implicit; thirdly it must be decided what are the objects of contradiction: whether they are sentences (token,types), statements, claims, propositions, or states of affairs; finally it must be said which type of negation is involved: whether classical negation or non-classical negation. These choices give rise to a potentially large number of formulations of LNC. ${ }^{4}$ Given the orthodox assumption that propositions are the objects of our attitudes and since we are primarily interested in the attitudes of disputing subjects, we will use the following semantic formulation: ${ }^{5}$

LNC (semantic reading) propositions $p$ and not $-p$ cannot be both true in the same circumstances.

where the notion of circumstance is intuitively taken to represent those aspects of reality against which the proposition is evaluated (possible worlds are the standard case).

Now that we have specified the reading of LNC that we will be using, it is time to get clear about the structure of the paradox by using as a working

\footnotetext{
${ }^{3}$ We use italics for referring to propositions.

${ }^{4}$ Patrick Grim (Grim 2004) has in fact calculated that there at least 240 possible formulations of LNC!

${ }^{5}$ See Berto $(2008,166-69)$ for a discussion of the semantic formulation.
} 
example a dispute on matters of basic taste. Let's illustrate it in details by means of the following utterances:

Mary: "Ginger is tasty"

Jane: "Ginger is not tasty"

Call these yes-no utterances, and let's conceive an utterance as an ordered couple $\langle s, c\rangle$ where $s$ is the uttered sentence and $c$ the context of use of the sentence relevant for the utterance. Intuitions related to the subjective character of taste discourse suggest that yes-no utterances must be equally valid. Suppose their equal validity involves that they their semantic status is on a par. If so, they must have an equal semantic status that does justice to their equal validity. The most natural hypothesis is thus that they are both true. Given an equivalence schema for utterance truth - if an utterance $\langle s, c>$ says that $p$ then ' $s$ ' is true in $\mathrm{c}$ iff $p$ - and an equivalence schema for propositional truth - it is true that $p$ iff $p$-, and given what yes-no utterances say, we have that, in the same world, the proposition that ginger is tasty and the proposition that ginger is not tasty are both true. By LNC these two latter propositions cannot both be true in the same world, hence, by reductio, we conclude that, despite the equal validity intuition, yes-no utterances cannot both be true. Thus yes-no utterances must differ in truth-value. Conclusion: the equal validity intuition cannot find a coherent formulation in terms of equality of truth of the utterances involved in a dispute of inclination.

Here is a semi-formal presentation of the argument:

(1) $<\mathrm{s}, \mathrm{c}>$ and $<\mathrm{s}^{\prime}, \mathrm{c}^{\prime}>$ are equally valid.

(2) If $<\mathrm{s}, \mathrm{c}\rangle$ and $\left\langle\mathrm{s}^{\prime}, \mathrm{c}^{\prime}\right\rangle$ are equally valid, then $\left\langle\right.$ s,c $>$ and $\left\langle\mathrm{s}^{\prime}, \mathrm{c}^{\prime}\right\rangle$ are both true wrt to the same circumstances.

(3) if $<\mathrm{s}, \mathrm{c}\rangle$ expresses $\langle\mathrm{p}\rangle$, then $(<\mathrm{s}, \mathrm{c}\rangle$ is true only if $<\mathrm{p}>$ is true in $\operatorname{circ}(<\mathrm{s}, \mathrm{c}>)$.

(4) if $\left\langle\mathrm{s}^{\prime}, \mathrm{c}^{\prime}>\right.$ expresses $<\mathrm{q}>$ then $\left(<\mathrm{s}^{\prime}, \mathrm{c}^{\prime}>\right.$ is true only if $\langle q\rangle$ is true in $\operatorname{circ}\left(<\mathrm{s}^{\prime}, \mathrm{c}^{\prime}>\right)$.

(5) $\quad<\mathrm{s}, \mathrm{c}>$ expresses $<\mathrm{p}>$.
(Equal Validity)

(Alethic Equal Validity)

(Utterance-Proposition Truth Schema)

(Utterance-Proposition Truth Schema)

(Propositionality) 


\begin{tabular}{|c|c|c|c|}
\hline 6 & $(6)$ & $<\mathrm{s}^{\prime}, \mathrm{c}^{\prime}>$ expresses $<\mathrm{q}>$. & (Propositionality) \\
\hline 1,2 & $(7)$ & $\begin{array}{l}<\mathrm{s}, \mathrm{c}>\text { and }\left\langle\mathrm{s}^{\prime}, \mathrm{c}^{\prime}\right\rangle \text { are both true wrt to } \\
\text { the same circumstances. }\end{array}$ & (Modus ponens:1,2) \\
\hline 3,5 & $(8)$ & $\begin{array}{l}<\mathrm{s}, \mathrm{c}>\text { is true only if }<\mathrm{p}>\text { is true in } \\
\operatorname{circ}(<\mathrm{s}, \mathrm{c}>)\end{array}$ & (Modus ponens: 3,5 ) \\
\hline 4,6 & $(9)$ & $\begin{array}{l}<\mathrm{s}^{\prime}, \mathrm{c}^{\prime}>\text { is true only if }<\mathrm{q}>\text { is true in } \\
\operatorname{circ}\left(<\mathrm{s}^{\prime}, \mathrm{c}^{\prime}>\right) .\end{array}$ & (Modus ponens: 4,6) \\
\hline $1,2,3,5$ & (10) & $<\mathrm{p}>$ is true in $\operatorname{circ}(<\mathrm{s}, \mathrm{c}>)$ & (Modus ponens: 7,8 ) \\
\hline $1,2,4,6$ & (11) & $<\mathrm{q}>$ is true in $\operatorname{circ}\left(<\mathrm{s}^{\prime}, \mathrm{c}^{\prime}>\right)$ & (Modus ponens: 7,9 ) \\
\hline 1,2 & $(12)$ & $\operatorname{circ}(<\mathrm{s}, \mathrm{c}>)=\operatorname{circ}\left(<\mathrm{s},{ }^{\prime} \mathrm{c}^{\prime}>\right)$ & (7) \\
\hline 13 & $(13)$ & $<\mathrm{q}>=<$ not-p $>$ & (Contradiction) \\
\hline $1,2,4,6,13$ & (14) & $<$ not $\mathrm{p}>$ is true in $\operatorname{circ}(<\mathrm{s}, \mathrm{c}>)$ & $(11,12,13)$ \\
\hline $1,2,3,4,5,6,13$ & $(15)$ & $\begin{array}{l}<\text { not } \mathrm{p}>\text { and }<\mathrm{p}>\text { are true in } \\
\operatorname{circ}(<\mathrm{s}, \mathrm{c}>)\end{array}$ & (Introduction of conjunction: 10,14 ) \\
\hline 16 & (16) & $\begin{array}{l}\forall \mathrm{P}, \mathrm{C}(<\mathrm{P}>\text { and }<\text { not-P }>\text { are not both } \\
\text { true in } \mathrm{C})\end{array}$ & $(\mathrm{LNC})$ \\
\hline $1,2,3,4,5,6,13,16$ & (17) & Contradiction & $(15,16)$ \\
\hline
\end{tabular}

The Equal Validity Paradox is generated by the following theses: (1) yesno utterances are equally valid (Equal Validity); (2) if yes-no utterances are equally valid then they are both true with respect to the same truth-value with respect to the same circumstances (Alethic Equal Validity); (3) yes-no utterances both express propositions (Propositionality); (4) these propositions are contradictory (Contradiction); ${ }^{6}(5)$ the alethic profile of the truth property for these utterances and the propositions expressed is governed by the utteranceproposition truth-schema (Utterance-Proposition Truth Schema); and, finally, (6) these propositions cannot both be true in the same circumstances (LNC). ${ }^{7}$

\footnotetext{
${ }^{6}$ We are appealing to contradiction because in the example in question are involved sentences of the from "p" and "not-p". The more general relation should be the one of incompatibility which can involve also being contraries.

${ }^{7}$ For a more detailed and slightly different reconstruction of the Equal Validity Paradox see Coliva and Moruzzi (2014b).
} 


\section{Six Ways Out of the Paradox}

A way to object to the paradox is to criticise the reasoning on the basis that some of inferences are invalid. We will set aside this solution since we do not think that objecting to modus ponens or conjunction introduction in relation to the inferences involved in the paradox is an helpful strategy for explaining of the nature of the paradox.

Given the structure of the paradox there are at least six solutions to the Equal Validity Paradox: (i) to deny Equal Validity; (ii) to deny Alethic Equal Validity; (iii) to deny Propositionality; (iv) to deny Contradiction; (v) to deny Truth Equivalences; and, finally, (vi) to deny LNC. In this section we will sketch these strategies.

\subsection{Strategy i: Revisionary Vs descriptive approaches}

Strategy (i) - i.e. the denial Equal Validity - consists in a revisionary approach to the problem. ${ }^{8}$ According to the revisionary approach disputes of inclination depend on a misguided view on the subject matter: when confronted with disputes of taste, for example, we wrongly think that both views are legitimate, whereas there is no sense of entitlement for these views capable of making sense of both views as rationally responsible attitudes - the only rational attitude is that of abstaining from believing and disputing. Such a radical stance on the problem denies the phenomenon we wish to account for -i.e. the intuition that subjective discourse has its own specificity. Of course, such a radical departure from our practice needs an articulated motivation, for the challenge for any revisionary approach is the possibility of elaborating a theory that offers a descriptive account of the phenomenon while at the same time solving the Equal Validity Paradox. Strategies (ii)-(vi) can then be seen as attempts to solve the paradox and to offer at the same time a descriptive account of faultless disagreement, whereas strategy (i) can be seen as the fallback strategy in case

\footnotetext{
${ }^{8}$ See for example Iacona (2007) for the thesis that there is no faultless disagreement.
} 
no other strategy is viable.

Before moving to the remaining solutions to the paradox it is important to stress the dialectical role of the Equal Validity Paradox with respect to the problem of faultless disagreement. Going revisionary means that the allegedly Equal Validity Paradox shows that our practice of judging and disputing about subjective domains is intrinsically misguided: no positive account can make sense of this practice as a rational practice, the paradox is thus taken as the symptom of the defectiveness of the practice. ${ }^{9}$ On the contrary, a descriptive account saves the phenomenon by rejecting some theoretical theses - i.e. theses 2-5 - involved in the paradox.

The challenge to any descriptive solution to the Equal Validity Paradox is thus the request to show that the theoretical revision invoked can indeed avoid a revisionary approach to the phenomenon - in other words the challenge amounts to the request of showing that the rejection of any of the theses 2-4 is consistent with the acceptance of thesis 1 .

In the following, five descriptive solutions to the Equal Validity Paradox will be outlined. These strategies can be divided in two camps: semantic strategies $(\S 3)$ and alethic strategies ( $\S 4)$. Semantic strategies appeal to the workings of the semantics of natural languages in order to block the paradox, whereas alethic strategies invoke some truth-property to show where the Equal Validity Paradox goes wrong. The paper will focus then $(\S 4.2)$ on the last descriptive strategy - strategy vi- which is based on a dialetheist rejection of LNC. In $\S 5$ a normative problem for strategy (vi) is developed and in $\S 5.1$ a possible solution to it is sketched. Finally, in $\S 6$ some connections between strategy six and pluralism on logic and truth are explored.

\footnotetext{
${ }^{9}$ Following Schiffer (2003), this solution is an "unhappy face" solution to the paradox.
} 


\section{Semantic strategies}

Semantic strategies include at least three strategies -i.e. rejection of either theses 2 , or 3 or 4 - which are well known in the literature. Yet for each of these routes there are well-founded doubts that they can actually avoid a revisionary approach to faultless disagreement. In this section we will sketch these strategies and will rehearse some worries on the feasibility of these options. ${ }^{10}$

\subsection{Strategy (ii): the denial of Alethic Equal Valid- ity - Realism, Contextualism and Relativism, Indeter- minism}

Strategy (ii) is the strategy shared by truth-relativists, non-indexical contextualists and realists. Alethic equal validity is rejected by realists who account for equal validity in epistemic terms, truth-relativist and non-indexical contextualist deny altogether Alethic Equal Validity by relativizing propositional truth to non-standard circumstances of evaluation. ${ }^{11}$

It is well-known what the difficulties for a realist treatment are: the price of preserving classical semantics is to make room for the existence of a fact of the matter on subjective questions - such as whether or not a piece of food is tasty - where it is hard to imagine what else, if not our judgements, could determine what the correct answer is. ${ }^{12}$ More importantly: if truth is so remotely connected to our practices of subjective judgements, it is difficult to describe these practices as rationally sustainable when it comes to the activity of disputing.

As for truth-relativism and non-indexical contextualism, these positions share the main difficulty in making sense of the idea of faultless disagreement

\footnotetext{
${ }^{10}$ See also Coliva and Moruzzi (2014b).

${ }^{11}$ For realism see Schafer (2011), Baker and Robson (2017); for assessment-sensitive relativism see Lasersohn (2005, 2013), MacFarlane (2014), for non-indexical contextualism (aka truth relativism) see Kölbel (2004).

${ }^{12}$ See Wright (2001).
} 
when the relativisation of propositional truth is in place: it becomes unclear, how according to non-indexical contextualism, two utterances, which are true at different circumstances, involve any incompatibility of their respective assertions; whereas truth-relativism does not seem to have a non-metalinguistic way to express the idea of faultlessness since from each perspective each subject is right is criticising the opponent's view. ${ }^{13}$

Another implementation of strategy (ii) is to argue that disputes of inclination operate in areas of discourse where there is no fact of the matter as to whether an utterance or a proposition is true. Call this strategy indeterminism. The main gist of indeterminism is that there is an "absence of mistake-makers " when yes-no utterances are involved (Beall 2006, 64), and this absence is due to the absence of any fact of the matter that would otherwise determine one of the utterances as incorrect. A natural way to implement indeterminism is to argue that yes-no utterances have a third semantic status different — and incompatible - with truth. A well known way to model this option is to adopt a strong Kleene semantics and hold that yes-no utterances have a gappy semantic status as they are neither true nor false.

The problem with indeterminism lies in the tension between the thesis of semantic under-determination as a third semantic status other than truth and falsity and the thesis of equal validity.

If we adopt the rather weak truth-norm:

Norm it is permitted to assert p only if $p$ is true

yes-no utterances (and their respective beliefs) would count as incorrect. ${ }^{14}$ Could we reasonably modify the norm for allowing that a gappy proposition is assertable?

\footnotetext{
${ }^{13}$ The critical literature on MacFarlane's relativism is huge. For some recent critical points see Moruzzi (in corso di pubblicazione), Wright (2007), Marques (2014), Ferrari (2016b), Raffman (2016), Stanley (2016), Wright (2016), Ferrari and Wright (2017).

${ }^{14}$ The debate on the normativity of truth is wide and complex. We are here assuming a rather weak norm. See Ferrari 2016 and ms for an analysis on the different varieties of normativity that could exert on truth.
} 
Norm* it is permitted to assert $p$ only if $p$ is true or gappy.

Being a gappy proposition would thus par with truth in being a semantic value compatible with the correctness of an assertion and a belief.

However Norm* cannot capture the normative role of a gappy proposition. As Dummett (1959) noticed, the normative role of a semantic value has a close connection with the notion of logical consequence: if a semantic value plays a central positive role for assertion, then it has a semantic status that plays a positive role for the practice of inferring deductively. Truth is such a semantic value in classical logic, where the only other semantic value is the false. Generalising from classical logic, Dummett pointed out that a designated value is a semantic value that plays the same role for logical consequence as the role played by truth in classical logic. Thus, on the model theoretic approach to logical consequence, being a designated value is being one of the values that are preserved in a deductively valid inference: in many-valued logic, validity is preservation of these designated values.

Now, if we grant these considerations, Norm* determines that the status of being gappy is a designated value, but that can't be right since in strong Kleene semantics the third value is interpreted as undesignated.

\subsection{Strategy (iii): the denial of Propositionality - Expressivism, Second-order indeterminacy}

Whereas the latter three positions agree on the idea that in disputes of inclination the discourse involves genuine propositions and hence it is truth-apt, strategy (iii) rejects the idea that yes-no utterances express genuine propositions; one way to make sense of this option is to go expressivist. ${ }^{15}$ Expressivism has been historically the preferred route for escaping the problem: given that no genuine proposition is involved, there is no point in making sense of the

\footnotetext{
${ }^{15}$ Ayer (1936) is the first example of this strategy in relation to aesthetics and morality. For contemporary examples of this strategy see Richard (2008), Huvenes (2012, 2014).
} 
truth-conditions of yes-no utterances. However, well known problems afflict the expressivist route, first and foremost the so-called Frege-Geach problem. ${ }^{16}$ Whether or not this daunting problem is genuine is beyond the scope of this paper. Suffice here to say that Schroeder (2008) has thoroughly elaborated the expressivist position concluding that the Frege-Geach problem is answerable only by incurring in heavy costs that compromise compositional semantics.

Another way to implement strategy (iii) is to hold that a yes-no utterance expresses one proposition but that it is indeterminate which one it actually expresses. Norm and this indeterminacy thesis jointly entail that it is indeterminate whether yes-no utterances are permitted. Note that this indeterminacy strategy is different from the gappy indeterminism mentioned in relation to strategy (ii). Whereas gappy indeterminism claims an indeterminacy regarding the truth-value of the proposition expressed (first-order indeterminacy), this indeterminacy thesis concerns which proposition is expressed by a yes-no utterance. Borrowing the terminology of Matti Eklund ${ }^{17}$, we can call this indeterminacy second-level indeterminacy and the indeterminacy of gappy indeterminism first-order indeterminacy.

The basic worry for this second-order indeterminacy strategy is that the indeterminacy in the content expressed casts doubt on the existence of a genuine disagreement: if Mary's utterance does not determinately express that ginger is tasty, then Jane's utterance does not determinately contradict what Mary has said. A further worry is related to the appropriate stance related to secondorder indeterminacy. If Mary fails to express a proposition determinately, it seems that the appropriate stance to have in this case is to withhold belief from any of the propositions that her utterance indeterminately expresses. Agnosticism seems thus the mandated attitude in disputes of inclination, and thus the proposal seems to fall back onto a form of revisionism.

\footnotetext{
${ }^{16}$ See Woods (forthcoming).

${ }^{17}$ Eklund (2010).
} 


\title{
3.3 Strategy (iv): the denial of Incompatibility - In- dexical Contextualism
}

\begin{abstract}
As to the strategy (iv) - the denial of Incompatibility - indexical contextualism is the case in point: indexical contextualists deny that the same proposition is involved in disputes of inclination; according to them the semantic content of evaluative expressions such as "tasty" is sensitive to the context of use. Whether or not the contextualist semantic story is credible, the most pressing problem for this strategy is the so-called lost disagreement problem: the difficulty of making sense of the idea of disagreement if yes-no utterances do not express incompatible contents. ${ }^{18}$

None of the previous considerations is of course intended to provide a knockdown argument against these proposals, nor it is the aim of this work to do so. What matters here is rather to show that there is a well-grounded suspicion that these solutions to the Equal Validity Paradox cannot but end up in being revisionary with respect to the phenomenon of faultless disagreement.
\end{abstract}

\section{Alethic Strategies}

Whereas the former strategies and their respective problems have been widely explored in the recent literature on faultless disagreement, the remaining two strategies — strategies (v) and (vi) - haven't received the same extensive treatment. Option (v) denies equivalence schema either for utterance truth or for propositional truth, whereas option (vi) rejects LNC. Since strategy (vi) is here considered via the adoption of dialetheism, this strategy can be conceptualised as the adoption of thesis that truth is not a consistent property. Since these two last options require the abandonment of some orthodox principles about truth, they are labeled alethic strategies.

\footnotetext{
${ }^{18}$ For the basic worry of the lost disagreement problem see Coliva and Moruzzi (2014a). For sophisticated forms of contextualism see de Sa (2015), Sundell (2011), Wyatt (forthcoming).
} 


\subsection{Strategy ( $\mathrm{v})$ : the denial of Utterance-Proposition Truth Schema}

According tho this strategy a yes-no utterance expresses a proposition but the truth of the utterance does not entail the truth of the proposition expressed:

$<\mathrm{s}, \mathrm{c}>$ expresses $<\mathrm{p}>$ and $<\mathrm{s}, \mathrm{c}>$ is true but $<\mathrm{p}>$ is not true in $\operatorname{circ}(<\mathrm{s}, \mathrm{c}>)$

Utterance-Proposition Truth Schema would thus fail. It is hard to find a principled motivation for this strategy, nor we do know of any proposal in the literature implementing this strategy. Few remarks will suffice for the purposes of this work. Given that yes-no utterances are true they are correct as speech acts. On the other hand, given that the propositions expressed by these utterances are not true in the relevant circumstances, believing these propositions would be incorrect. ${ }^{19}$ It would follow that the correctness conditions belief and assertion potentially diverge. When Mary utters "Ginger is tasty" her linguistic move is correct, while her internal representation of the taste of ginger is mistaken. One way to make sense of this option is to hold a pragmatic story explaining why assertions about taste such as Mary's are correct, while at the same holding an error theory about taste-properties: there is no genuine taste property, but only physiological properties that play a different role from the evaluative role that in our ordinary talk we attribute to taste-vocabulary.

The basic problem with this way of implementing strategy $(\mathrm{v})$ is that it is clearly committed to a revisionary stance: we are systematically mistaken in having beliefs about what is tasty. ${ }^{20}$

\footnotetext{
${ }^{19}$ Notice that in order to avoid violation of LNC, it should claimed that either a) one proposition is true and the other is false; or b) the propositions expressed are not contradictory; or $\mathrm{c}$ ) that $<\mathrm{p}>$ is untrue (but not false) and that $<$ not-p $>$ is false. As for option a), it seems tantamount to realism, so option a) collapses into strategy (ii). Analogously, option b) seems just indexical contextualism, so we have a collapse into strategy (iv). Finally, option c) requires to adopt some version of threevalued semantics with a value (call it "untruth only") that is excluded by truth of a negation. This latter option seems the most promising option for avoiding the collapse into other strategies.

${ }^{20}$ Assuming that propositions are objects of belief.
} 


\subsection{Strategy vi: the denial of LNC - Dialetheism}

The last option is to deny LNC. This can be done by claiming that yes-no utterances express propositions that are both true and false. From a logical point of view, being true and false is here treated as a the third semantic status which is designated. This third status is the dual status of a truth-value gap: a truth-value glut. The most popular logic for modeling this view is LP - the Logic of Paradox - which is exactly like strong Kleene semantics except that the third value is designated. ${ }^{21}$ This brings us to see option vi a more promising solution than the gappy theory: dialetheism.

According to dialetheism, LNC fails ${ }^{22}$ since a yes-no utterance expresses a proposition that is a dialetheia - i.e. a proposition that is both true and false. This latter solution seems more promising: since a dialetheia is both true and false, it is also false but its falsity does not imply its untruth and thus Norm* does not evaluate yes-no utterances as incorrect.

Whether or not a contradiction is acceptable is, for a dialetheist, a question to decide case by case. According to Priest, there seems to be no general criterion for deciding whether or not a contradiction is rationally acceptable. ${ }^{23}$ The

\footnotetext{
${ }^{21}$ The idea of using dialetheism for accounting for the phenomenon of faultless disagreement is sketched in Beall (2006) where it is claimed that analetheism - which interprets gappy propositions as designated - is a better option. See Beall and Ripley (2004) for a presentation of analetheism. Beall (2006) prefers this strategy to dialetheism in relation to taste on the grounds that analetheism makes sense of the idea that there is no fact of the matter in matters of sense (taste propositions are neither true nor false). We agree with Armour-Garb and Priest (2005) in thinking that analetheism does not do justice to the truth-norm for the same problems we have raised before in relation to the indeterminist gappy theory (see supra 3.1). Insofar as truth is the norm for assertion, we do not think that this model of indeterminacy is sufficient for accounting for the rational sustainability of a dispute. We will thus focus on dialetheism.

${ }^{22}$ Recall that we are using a semantic reading of LNC. In LP the formula $\neg(p \wedge \neg p)$ is never false only since, when $p$ is dialetheia, the formula itself is a dialetheia.

23 "I am frequently asked for a criterion as to when contradictions are acceptable and when they are not. It would be nice if there were a substantial answer to this question - or even if one could give a partial answer, in the form of some algorithm to demonstrate that an area of discourse is contradiction
} 
phenomenon of equal validity could then be a reason to accept a contradiction as true.

This dialetheist solution to the Equal Validity Paradox allows one to say that in a dispute where Mary asserts that ginger is tasty and where Jane denies it, Mary's and Jane's opposite judgements are actually contradictory, so no hidden or extra parameters are invoked for relativizing yes-no utterances' truth (as opposed to contextualism or truth-relativism); moreover it allows one to maintain that Mary's and Jane's judgements are equally valid because of they are value gluts.

Note that this solution can be seen as very similar to a relativistic solution in the following sense. Though it is difficult to state precisely what a fully general relativistic doctrine is, we can try to gesture at least at the spirit that has motivated relativistic proposals. Relativism finds its inspiration in the basic and rough idea that there are areas of discourse where we cannot describe reality in absolute terms without falling into contradiction. This thought can be developed in two ways: i) in a metaphysical way by claiming that reality is somehow richer than what is described by any individual consistent description; ii) alternatively, it can be developed in terms of representation by claiming that our ways of describing reality are expressively incapable of providing an absolute and coherent description of it. ${ }^{24}$ Now, historically this basic thought has been developed by introducing some mechanism of relativisation because the idea of embracing a contradiction was abhorred. ${ }^{25}$ However, if this rough description of the basic relativistic thought is right, it is perfectly consistent with the relativistic spirit to go dialetheist by claiming that there is no consistent

free. But I doubt that this is possible. Nor is this a matter for surprise. Few would now seriously suppose that one can give an algorithm - or any other informative criterion - to determine when it is rational to accept something. There is no reason why the fact that something has a certain syntactic form - be it $p \wedge \neg p$ or anything else - should change this. One can determine the acceptability of any given contradiction, as of anything else, only on its individual merits." (Priest 1998b, 423).

${ }^{24}$ Coliva (2009), Baghramian and Coliva (forthcoming).

${ }^{25}$ Aristotle (Metaphysics, $\Gamma$ 4) famously held that LNC cannot admit exceptions. See Priest (1998a) for a discussion of Aristotle on LNC. 
absolute description of reality because in some areas of discourse contradictions are true. In analogy with the metaphysical and representational version of the basic relativistic thought, dialetheist relativism can mirror these two versions by adopting, respectively, either metaphysical dialetheism (e.g. there are inconsistent facts in the subjective domain) or semantic dialetheism (e.g. natural languages are intrinsically inconsistent when it comes to areas of subjective discourse; see Mares (2004) for the distinction).

To sum up, dialetheism has a way of dealing with the contradiction involved in a dispute that gives rise to faultless disagreement. It also seems capable of avoiding the problems that contextualist proposals usually face - namely the disappearance of disagreement. At the same time it distances itself from truthrelativism in making sense of equal validity, while truth-relativists have no way to make sense of the idea that relatively to the same parameter, to which truth is relativized, both opinions are equally valid.

In the following sections strategy (vi) will be scrutinised in detail in order to assess its stability.

\section{The Normative Problem for Strategy (vi)}

Consider again our yes-utterances: Mary utters "Ginger is tasty" and Jane utters "Ginger is not tasty". Suppose that basic taste discourse exhibits faultless disagreement and that dialetheism should be applied to it. Incompatibility between the utterances would fail: both parties should admit that also their opponent is right, not just from her own point of view, but tout court. This consequence is itself a virtue of this strategy since it satisfies what Crispin Wright has dubbed Parity:

[...]it is the requirement that faultlessness be appreciable, and endorsable, from the point of view not just of neutrals but of the committed parties in a dispute (Wright 2012, 439)

In addition to Parity, Wright (2012) lists three other features of a dispute involving faultless disagreement. Two of these features are mentioned in the Equal 
Validity Paradox: Contradiction (equivalent to the principle Incompatibility) and Faultlessness (equivalent to Equal Validity). To these features Wright adds Sustainability: that is perfectly rational for the disputants to hold on disputing.

In the dialetheist setting Parity seems to jeopardise the sustainability of the dispute: if Mary thinks that Jane is not faulty in thinking that ginger is not tasty because Mary recognises that it is true that ginger is not tasty, and if Jane recognises that Mary is not faulty in thinking that ginger is tasty, then given they respective beliefs, they seem to have no real disagreement insofar as the latter requires a belief in the incompatibility concerning the truth of the contents believed. They should therefore cease to quarrel since they should both recognise that also the other party is right. The normative significance of holding contradictory contents evaporates since it does not involve any genuinely sustainable disagreement. Strategy (vi) thus collapses into a form of revisionism instead of being a plausible way of pursuing a descriptive project: instead of delivering a description of a targeted area of investigation that matches with our ordinary representation of it, the dialetheist delivers a description of the area of investigation that does not match with our ordinary representation of it. $^{26}$

Assume the previous norm of assertion is in place:

Norm it is permitted to assert $p$ only if $p$ is true

The latter considerations can then be presented as a normative elaboration of a familiar problem for dialetheism in making sense of an exclusive notion of negation (Parsons 1990, Batens 1990, Berto 2008):

\section{ARGUMENT 1 :}

1. Suppose $p$ is a dialetheia and that A and B have evidence for this;

2. Suppose A asserts $p$;

3. Suppose B's typical of way of disputing with A is by asserting not- $p$;

\footnotetext{
${ }^{26}$ This normative problem in relation to faultless disagreement is outlined in Coliva (2009, 151-52). See also Wright $(2012,438)$.
} 
4. B's assertion of not- $p$ does not prevent her from also accepting $p$ (since $p$ is a dialetheia Norm is respected);

5. Incompatibility between A and B's assertions is lost;

6. The dispute between $\mathrm{A}$ and $\mathrm{B}$ on $p$ is not rationally sustainable.

In a nutshell, the problem stems from the nature of the dialetheia: if a proposition is a dialetheia, the mutual correctness of accepting the proposition and its negation does not seem to leave space for any substantial disagreement: both accepting $p$ and rejecting $p$-intended as accepting not- $p^{27}$ — are correct. So opposite attitudes over $p$ do not seem to motivate any rational dispute.

A possible way out of this problem is to distinguish four notions in play here (Priest 2005, 96-99) (Priest 2006, 103):

Acceptance of $p=$ mental state of believing $p$;

Assertion of $p=$ the speech act of expressing the act of accepting $p$;

Rejection of $p=$ the mental state of refusing to believe $p ;{ }^{28}$

Denial of $p=$ the speech act of expressing the act of rejecting $p$.

Here is how Priest explains these distinctions:

Someone who rejects A cannot simultaneously accept it any more than a person can simultaneously catch a bus and miss it, or win a game of chess and lose it. If a person is asked whether or not A, he can of course say 'Yes and no'. However this does not show that he both accepts and rejects A. It means that he accepts both A and its negation. Moreover a person can alternate between accepting and rejecting a claim. He can also be undecided as to which to do. But do both he can not. (Priest 1989, 618)

\footnotetext{
${ }^{27}$ The equivalence between acceptance of not- $P$ and rejection (or denial) of $P$ is known as "denial equivalence" in Ripley (2015) and as "classical denial" in Murzi and Carrara (2014). Also gappy theorists reject this equivalence - see Parsons (1984).

${ }^{28} \mathrm{We}$ can interpret acceptance of $p$ and rejection of $p$ as "yes-or-no questions, respectively reading A? Yes! and A? No!.” (Murzi and Carrara 2014, PAGE).
} 
Hence acceptance and rejection are exclusive (but not exhaustive, agnosticism is always a third possible stance). Familiar examples in which these distinctions are applied are gappy sentences (given that a sentence can be untrue without being false, having ground for the denial of $p$ and not- $p$ does not ground, respectively, the acceptance of not- $p$ and of $p$ ) and, crucially here, glutty sentences: given that a sentence can be false without being untrue, having ground for the acceptance of $p$ and acceptance of not- $p$ does not ground, respectively, denial of not- $p$ and of $p$. Priest's point (Vs Frege \& Geach) is thus that denying $p$ does not always involve asserting not- $p$.

Now let's assume this notion of rejection, at least for the sake of the argument, though it is unclear what information is conveyed by a subject's denial. ${ }^{29}$ A way to express incompatibility between attitudes can then be regained: the correctness of A's acceptance of $p$ excludes the correctness of B's rejection of $p .^{30}$

Given this distinction, Priest $(2006,110)$ states three different normative principles for rationality involving acceptance and rejection:

(Accept-p) One ought rationally to accept $p$ if there is good evidence for the truth of $p$.

(Accept-Not-p) One ought rationally to accept not- $p$ if there is good evidence for the falsity of $p$.

(Reject-p) One ought rationally to reject $p$ if there is good evidence for the untruth of $p$.

First, these principles are epistemic norms and not alethic norms — principles

\footnotetext{
${ }^{29}$ See Grim (2004), Berto (2008). Berto $(2008,174-8)$ states some worries regarding the idea that acceptance and rejection are primitively exclusive mental states. Berto argues that it is better to explain this incompatibility between attitudes through a notion of content exclusion. We agree with Berto's point, however this issue will not be crucial for the following discussion.

${ }^{30}$ In other words the exclusivity relation between acceptance and rejection involve that accepting $p$ and rejecting $p$ cannot be jointly correct attitudes. For the notion of joint correctness and its relation to disagreement see MacFarlane (2014, PAGE).
} 
about what is rational to believe on the basis of evidence for the truth of a proposition and not principles about what is permitted to believe in relation to the truth-value of a proposition. Second, note the Reject-p is not an exclusive norm for rejection since accepting $p$ and rejecting $p$ can be jointly correct attitudes. An exclusive norm would be

(Reject-p-Ex) One ought to reject $p$ if $p$ is untrue.

However, Murzi and Carrara (2014) have argued that an exclusive denial norm - plus the assumption that denial is expressible in the language - gives rise to a paradox once very minimal assumptions are in place. ${ }^{31}$

Contrary to the norms for exclusive denial, Reject-p does not make assertion and rejection normatively incompatible. However, according to Priest, these acts cannot be performed at the same time and hence, though they are not normatively incompatible, they are nonetheless metaphysically incompatible: given any proposition $p$ a subject cannot perform both the act of accepting $p$ and the act of rejecting $p$. Murzi and Carrara object against the metaphysical impossibility (Murzi and Carrara 2014, PAGE).

In order to recapture the normative incompatibility between acceptance and rejection, we could modify the rejection rule as follows:

(Reject-p*) One is permitted to reject $P$ if there is good evidence for $P$ s untruth, unless there is also good evidence for its truth. ${ }^{32}$

According to Reject-P* one may deny $P$ if one has good reasons for thinking that $P$ is untrue only.

Carrara and Murzi criticise this norm on the basis of its asymmetry with the acceptance norm:

\footnotetext{
31 "If denial is to serve as a means to express disagreement, it must be rationally impermissible to both assert and deny A. Yet, in view of the Paradox of Deniability, no comprehensive set of norms for exclusive denial can be formulated in the glut-theorist's language." (Murzi and Carrara 2014, PAGE). See also Ripley (2015) for similar worries.

${ }^{32}$ This a modified version considered by Murzi and Carrara (2014) under the label "Deny(U)*".
} 
Unlike assertion, any denial may later turn out to be incorrect, since any false sentence can in principle be discovered to be a glut. Thus, you can disagree with my assertion that $0 \neq 0$, and thus deny $0 \neq 0$. But, even if you can prove $0=0$, and hence disprove $0 \neq 0$, you can never be fully confident that your denial is correct: a proof of $0 \neq 0$ may always turn up. By contrast, if you have proved $0=0$ and thereby assert it, you can be fully confident that your assertion is correct.We find this asymmetry problematic: nothing in our practice of asserting and denying things, it seems to us, suggests that assertion can be indefeasible in a way that denial is not.

(Murzi and Carrara 2014)

In the quoted passage it seems crucial that evidence for accepting $0=0$ is a proof, and thus an indefeasible evidence. At the same time the evidence for the rejection $p$ sufficient for rejecting $p$ is defeasible: once it is discovered that $p$ is a dialetheia its rejection becomes unpermitted for the subject. But this argument assumes that assertion always requires indefeasible evidence. However in many other (non mathematical) cases the evidence for a proposition is feasible: I believe that this fish is a mackerel but I am wrong due to bad lighting conditions. ${ }^{33}{ }^{34}$ If we bracket this issue we nevertheless have the following problem:

\section{ARGUMENT 2 :}

1. Suppose $p$ is a dialetheia and that A and B have evidence for this.

2. Suppose A asserts $p$.

\footnotetext{
${ }^{33}$ It is also doubtful that in mathematics the evidence for an assertion must always be a proof.

${ }^{34}$ The other option Carrara and Murzi consider is Beall (2013)'s proposal according to which we can add the so-called shriek-rules to express that a sentence is true-only. For each sentence A which is not glutty it is added a non-logical rule of the form: $A, \neg A \vdash \perp$, where ' $\perp$ ' is an operator that implies triviality. By means of the shriek-rules we can then express that a theory is consistent by stating shriek-rules for all the predicates - a shrieked theory. A shrieked-theory is thus either consistent or trivial. Notice, however, that this proposal will not work if the dialetheist position for the Equal Validity Paradox entails local triviality as argued below — see infra $\S 6$.
} 
3. Suppose B's way of disputing with A is rejecting $p$.

4. B's rejection of $p$ prevents her from also by accepting $p$ (Incompatibility satisfied).

5. But since $p$ is a dialetheia and $\mathrm{B}$ has evidence of it, $\mathrm{B}$ is not permitted to reject $p$ if $\mathrm{B}$ has evidence for the truth of $p$ (Reject-p*).

6. B ought not rationally to reject $p$ (ditto for A wrt not- $p$ ).

7. The dispute between $\mathrm{A}$ and $\mathrm{B}$ on $p$ is neither faultless nor rationally sustainable.

The conclusion of Argument 2 is thus worse than the conclusion of argument of 1 for the dialetheist solution to the Equal Validity Paradox: assuming that both subjects have evidence that $p$ is a dialetheia, not only can we make no sense of the rationality of the dispute, but B's rejection of $p$ is also incorrect. Hence,faultlessness is lost. Therefore, a dispute on matters of inclination cannot be presented as involving the norm of rejection. However, the mere acceptance of a proposition and of its negation does not justify any sense of genuine disagreement between the parties to the disputes.

In principle there are several reasons why a subject could start disputing over a proposition that has been recognised a dialetheia. She could, for example, be interested in persuading the other subject to endorse some course of action instead of a different one. The point of ARGUMENT 2 is that there are no epistemic reasons (reasons for believing) that could motivate a dispute once a dialetheia is recognised. We think that precisely for this reason a dialetheist strategy (vi) must go revisionary in the end.

In conclusion, arguments 1 and 2 set up a dilemma for a dialetheist solution to the Equal Validity Paradox: either a dispute between subjects A and B involves A's acceptance of a proposition and B's mere acceptance of its negation; or else, it involves A's acceptance of a proposition opposed to B's rejection of it; if the former, incompatibility between the correctness of subjects' attitude is lost and hence, if the dispute is rational, ignorance of the fact that the proposition is a dialetheia must be then imputed to subjects (they mistakenly take acceptance 
of the negation of the proposition to be equivalent to the rejection of it). If, on the other hand, the dispute between subjects A and B involves A's acceptance and B's rejection of a proposition, B's rejection could be rational only insofar as she ignores that the proposition is a dialetheia, for recognition that the proposition $p$ is a dialetheia involves recognition that both $p$ and not- $p$ are true and hence that rejection of each is incorrect. In both cases the idea that the dispute is rationally conducted and sustainable is at odds with the assumption that subjects have correct beliefs about the dialetheic status of the proposition. Hence strategy (vi) is committed to a form of revisionism and it no longer seems a promising strategy for making sense of a descriptive solution to the Equal Validity Paradox.

\subsection{The epistemology of dialetheias}

A natural answer to the normative problem raised so far is to deny the assumption that both subjects have evidence of the dialetheic status of $p$. Perhaps in this way the rationality of the dispute could be regained.

The assumption that both subjects have evidence that the relevant proposition is a dialetheia needs more careful scrutiny. The crucial question is: how can subjects acquire evidence that a proposition on matters of taste is a dialetheia? Consider again the proposition that ginger is tasty. Mary tastes ginger finding it tasty, whereas Jane (tasting the same piece of ginger) finds it disgusting. At the time of tasting neither of them has first-order evidence i.e. evidence coming from their senses - that ginger is different from how their respective tastes presently inform them it is. After expressing their own views, they have nonetheless higher-order evidence - evidence coming from what the other believes - that ginger is different from how each of them finds it. Suppose they are open to the view that the proposition that ginger is tasty is a dialetheia: each subject would both have (first-order) evidence for the proposition she has asserted and (second-order) evidence for the opposite proposition. Assuming that Mary and Jane are epistemic peers with respect to tasting gin- 
ger, they would thus have evidence that the proposition that ginger is tasty is a dialetheia. Would they be irrational in disputing given this epistemic situation?

The standard problem in the epistemology of disagreement is how it can be rational to disagree with an epistemic peer: the root of the problem comes from the intuition that if evidence is knowingly shared by subjects with the same skills and if it is agreed that only one view can be right, then the responsible attitude to take, once disagreement comes into light, is agnosticism. If I believe a proposition based on some evidence, further evidence that a peer takes a different and incompatible view is in its turn evidence against that proposition. Such evidence undermines the rationality of my belief. However, once we drop the belief that the propositions in play are incompatible, the problem vanishes: the evidence for the opposite view does not automatically speak against my own view. So the question of the rationality of disagreeing between epistemic peers in the case of a dialetheia cannot be framed as the standard problem of the epistemology of disagreement.

The problem for the dialetheist strategy to the Equal Validity Paradox is in fact different, it is the problem of making sense of why Mary and Jane, say, should take one view and not both if they don't believe that their views are incompatible. To put the problem in a nutshell: if they have evidence that the proposition that ginger is tasty is a dialetheia, why should not they believe this proposition and its negation? But if they believed both propositions, then any sense of there being a rationally sustainable dispute would vanish on the assumption that both subjects have evidence that the proposition is a dialetheia.

Here is one way to answer this epistemological worry. Notice that each subject has access to different pieces of evidence for the two views: one piece is first-order (coming from the senses) for each view, the other is second-order (coming from the acknowledgement of the view of the other) for the opposite view. Following a suggestion made by Kelly (2005), there is a problem in the role that second-order evidence plays for deciding what to believe when this evidence is grounded in a belief based on the same body of evidence as the one on which one's belief is based. More specifically: If Mary credits the second- 
order evidence that Jane believes that ginger is not tasty as a further evidence relevant to deciding what to believe, she then gives additional weight to Jane's belief that ginger is not tasty is true when she has already considered (to the best of her ability) all first-order elements on which Jane's belief is based. Kelly's point is that this additional weight is suspicious.

Kelly's point can be developed in a slightly different direction: the secondorder evidence coming from the opponent's view cannot be as strong as my first-order evidence, in particular not strong enough to justify a belief in the opposite view. Nonetheless, this second-order evidence is evidence that the proposition that ginger is tasty is a dialetheia. So here there might be an explanation of why it is rational to have different beliefs while at the same time having evidence that a proposition is a dialetheia: I do not believe that the propositions that ginger is tasty and that ginger is not tasty are incompatible, for all I know I am open to believe that they can both be true. I taste ginger and, because of my subjective physiological reactions, I feel a pleasant flavour and, because of this evidence, I form the belief that ginger is tasty. Later on, a subject that I consider an epistemic peer forms the opposite belief, while tasting the same piece of ginger. However, I do not thereby form the belief that ginger is not tasty. Not because I exclude the presence of a dialetheia, but because the considerations of the opponent are based on the same evidence that has led me to believe that ginger is tasty. Nonetheless the fact a peer has an opposite opinion provides evidence for the view that ginger is not tasty. Still, this evidence does not play a role in forming or maintaining a belief that ginger is not tasty, but it plays the role of making me suspicious about the uniqueness of the correctness of my view, that is why I am open to discussing the matter further.

The former explanation, if successful, can, at best, explain why it is rational to take different views given the asymmetry of the type of evidence for the propositions forming a dialetheia. It remains however an open problem how to justify the rationality of sustaining different views once subjects have the same type of evidence for the truth of the propositions forming the dialetheia. Thus, 
it seems that if we grant knowledge of the dialetheist solution to the Equal Validity Paradox to subjects involved in a dispute of taste, they should not be prevented from believing both propositions, and thus any sense of disagreement would vanish once again.

\section{Dialetheism, Trivialism and Pluralism}

Call a domain of discourse a set of propositions that concern a certain subject matter. $^{35}$ It is not easy to define what a subject matter is, but we have an intuitive grasp of this notion when we say that the domain of morality is made of propositions that concern what is good and bad, that the domain of mathematics is the set of propositions that concern abstract properties such as being a set or being the sum of two numbers etc... Now the Equal Validity Paradox does not just arise for scattered couples of propositions that are related to yes-no utterances, rather it arises for a whole set of propositions that belong to a domain of discourse. Thus Mary and Jane's yes-no utterances concern the subject matter of basic taste: what is tasty, disgusting, delicious and so on. Hence, if the Equal Validity Paradox arises for Mary and Jane's yes-no utterances, then it quite plausibly arises for the whole domain of basic taste.

If the Equal Validity Paradox targets at least an entire domain, then strategy (vi) involves a form of "local atomic trivialisation" for domains of discourse: whereas paradoxical statements are a limited class of sentences, applying dialetheism to all domains of discourse targeted by the Equal Validity Paradox would imply that at least all atomic sentences belonging to those domains would be true and false. Not just isolated true contradictions, but a lot of our statements would present truth-value gluts.

Now it is well known that if all the atomic sentences of a language whose logic is given by LP are dialetheias, then this entails the existence of a trivial model for the language: in fact it is a property of this logic that if all atomic

\footnotetext{
${ }^{35}$ For issues related to domains of discourse see Wyatt (2013).
} 
sentences are both true and false, then all sentences are true and false. ${ }^{36}$

There are no logical reasons against trivialism. It has been argued that trivialism cannot be easily dismissed as logically absurd (Priest 2000, Priest 2005, ch.3 and Kabay 2010). Some have argued against it on the basis of its theoretical uselessness (Beall 2009, 34), others (Plebani 2015) that there are statistical reasons for thinking that it is false.

Though global trivialism has been defended (Kabay 2010), it is a very radical position to accept for it is unclear what would constitute a general reason for accepting all kinds of contradictions and it is very difficult to provide different justifications for every domain of discourse. In fact, the standard motivations for holding that a proposition is a dialetheia - e.g. reasons ranging from semantic paradoxes such as the Liar, to set-theoretic paradoxes such as Russell's paradox, or to metaphysics such the problem of change etc.- do not seem to be systemic enough to be generalisable to all atomic sentences of a domain. A fortiori they do not seem a sufficient motivation for considering all atomic sentences in all domains as dialetheias.

The previous considerations entail that if you assume a logically monist stance on dialetheism - i.e. LP is the only correct logic-, then global trivialisation will arise only insofar as you think that the Equal Validity Paradox arises for atomic propositions belonging to all domains of discourse. The idea that the equal validity paradox arises for all atomic propositions can be seen as an extreme form of relativism - let's call this position global atomic equal validity. If we conceptualise a judgement directed towards an atomic proposition as a judgement attributing properties or relations to objects -i.e. as representing that certain things are related in such and such way - then the thought of global atomic equal validity is that it is always equally correct to hold that objects are related so and so and to hold the contrary opinion. Global atomic equal validity is a difficult doctrine to accept. Can this doctrine be stabilised in

\footnotetext{
36 "LP has its so-called trivial model: if all atomic sentences of the relevant language are both true and false (or both true and false at the base world where truth is evaluated, if we have a worlds semantics for LP plus arrow), then all sentences are true and false." (Berto 2008, 170).
} 
order to avoid the collapse into global triviality —i.e trivialism for all domains?

The trivial model property for LP entails that if you hold global atomic equal validity and you think that dialetheism is the right answer to the Equal Validity Paradox for all domains, then you get full triviality for all domains. Given full triviality, everything is true and hence equal validity holds for all propositions. Thus, to conclude, global atomic equal validity, logical monism and dialetheism constitute a cocktail for an extreme form of global relativism: global trivialism. Hence, if you don't like global trivialism, you had better give up either global atomic equal validity or logical monism or dialetheism.

Thus a moderate implementation of strategy (vi) is to hold that the logic of dialetheism is the logic of all domains of discourse -i.e. to be a dialetheist logical monist - and to deny global atomic equal validity - i.e. only in some domains such as the domain of basic taste all atomic propositions ${ }^{37}$ are dialetheias. Assuming that the dialetheist semantics is given for all domains, no trivial model would then follow.

Another moderate implementation of strategy six is to hold on to dialetheism, to deny global atomic equal validity because you think that equal validity holds only in some domain of discourse and to have a pluralist stance on logic. ${ }^{38}$ In fact if there is more than one relation of logical consequence, ad if logical pluralism is domain-based -i.e. each domain has its own correct logicthen global trivialism is avoided. Notice, however, that if the dialetheist is a domain-based logical pluralist and if she holds that dialetheism is the solution to the Equal Validity Paradox, then in all domains targeted by the Equal Validity Paradox you will end up with local atomic trivialisation. Such a position would then be committed not to global trivialism -i.e. all propositions are true-, but to a local form of trivialism: all propositions of a domains - such as the domain of basic taste - are true. Whether or not this result is problematic, it can be shown to be an interesting consequence in relation to the theory of truth.

\footnotetext{
${ }^{37}$ Together with all the other propositions targeted by the dialetheist such as the liar, Russell's paradox, sentences expressing change etc.

${ }^{38}$ For domain-based logical pluralism see Lynch (2009, ch.5), Pedersen (2014) and Pedersen (n.d.).
} 
In fact, local atomic trivialisation can be seen as the idea that truth has the property of being inconsistent in certain domains. Would this be a new form of alethic pluralism? ${ }^{39}$ Only if we can stabilise the idea of local trivialism and we can make the case that the property of being inconsistent fits the alethic pluralist framework as a property that can play the truth role.

Is local trivialism untenable? Surely it is an extreme position. But notice that the arguments given by Priest against global trivialism do not apply to a form of local trivialism motivated by the faultless disagreement in the domain of basic taste. In fact, Priest (2005) argues against three possible arguments for (global) trivialism. First, he considers empirically-based evidence for trivialism. One way to argue from empirical evidence to trivialism is to hold that optical illusions related to colours are evidence for the more general thesis that all states of affairs are inconsistent:

How do I know that the room does not go red and green all over when I put on the glasses? Again, the facts that only I see it in this way, that the colouring comes and goes with the glasses, etc., clearly make the hypothesis that the colouring is subjective a superior one. (Priest 2005, §3.5)

But this line of argument is not effective against an empirically based evidence related to the phenomenon of faultless disagreement in relation to basic taste. If we take seriously the idea of disagreement, then faultless disagreement in the discourse of basic taste might be taken as empirical evidence for the existence of dialetheias.

Priest's second argument against trivialism is centred on the idea that assuming that the acquisition of meaning requires contrastive applications (correct and incorrect applications of expressions), trivialism implies that language is meaningless since there are correct applications only. Priest's himself recognises that this argument is not effective against trivialism:

"They may not be able to assert anything, but that does not stop them [from] uttering things. They may take themselves to be just babbling - to use

\footnotetext{
${ }^{39}$ For alethic pluralism see Lynch (2009) and the collection Pedersen and Wright (2013).
} 
a helpful phrase of Peter Unger. But we don't; and we still have to take into account the force of what they say, or at least, of what we take to be that force." (Priest 2005, §3.8)

Moreover the objection is less forceful against local trivialism, since the local trivialist might argue that the acquisition of the language of the domain in question - e.g. taste predicates - is secondary to the acquisition of the language of other non trivial domains.

The third argument against trivialism is a sort of "transcendental deduction from certain features of consciousness to the impossibility of being a trivialist" (Priest 2005, §3.9): the argument is based on the idea that choosing is intending to bring about a state of affairs, but "One cannot intend to act in such a way as to bring about some state of affairs, s, if one believes s already to hold". The trivialist believes that everything already holds, hence the trivialist cannot choose. But is it part of our phenomenological life that we (including the trivialist?) ought to choose. Thus, "We cannot, therefore believe everything to be the case about this world." Hence, we have a sort of transcendental argument against trivialism.

However suppose you have trivialism for the domain of basic taste. What is intending to act for basic taste propositions? Does Mary intend to act to bring about that ginger is tasty? Mary intends to act for tasting ginger, but the latter is not a basic taste proposition. Mary tastes ginger and then she judges that ginger is tasty. Her purpose was to taste ginger, once the purpose has been reached she has deliberated that ginger is tasty. However Mary did not act to bring about that ginger is tasty, nor to bring about her deliberation that ginger is tasty. It could be replied that if May intended to eat ginger she would be unable to choose what to eat in the future, assuming, as seems plausible, that in general we choose to eat tasty food and to avoid food we don't consider tasty. The objection would be effective if Mary's evidence for thinking that ginger is tasty were the same as her evidence for thinking that ginger is not tasty. However, crucially, Mary's evidence for thinking that ginger is tasty is stronger than her evidence for thinking the contrary as we have argued before 
(see supra 5.1). Hence, Mary can rationally choose what to eat in the future even if basic taste propositions are dialetheias.

Priest's objections to global trivialism thus do not apply to local trivialism. Whether or not local trivialism is acceptable is not easy to answer. On the one hand, it offers a dialetheist solution to the Equal Validity Paradox leaving open the possibility that truth is realised by different properties in other domains. On the other hand, it endangers to destabilize the intelligibility of the targeted domains. Thus, whether or not a dialetheist solution to the Equal Validity Paradox should embrace local trivialism depends on the reasons we have for being pluralist. If the explanatory advantages gained with pluralism overcome the disadvantages of local trivialism, then local trivialism can be overall acceptable. Otherwise, better to pursue strategy (vi) in a monist framework.

\section{Conclusions}

Of the five descriptive strategies to solve the Equal Validity Paradox, the dialetheist implementation of strategy (vi) is in danger of not doing justice to the rational sustainability of disputes related to the phenomenon of faultless disagreement. Strategy (vi) thus risks to fall back onto strategy one - the revisionary strategy - a danger shared by all other descriptive strategies. In this work it has been argued that strategy (vi) has some space for resisting the revisionary challenge and that pursuing strategy six might have interesting consequences for pluralism about truth. In fact, if strategy (vi) is applied to some domains only — like the domain of basic taste - it provides new motivations for claiming that in these domains truth is inconsistent. If in other domains truth turns out to be realised by truth-properties such as coherence, correspondence or super-assertability that are not inconsistent, we would have a new case for alethic pluralism.

Whether or not strategy (vi) amounts to the most stable solution to the Equal Validity Paradox is still an open question, but a question that is worth enquiring. 


\section{References}

Armour-Garb, B. and Priest, G.: 2005, Analetheism: A pyrrhic victory, Analysis 65(286), 167-173.

Ayer, A. J.: 1936, Language, Truth and Logic, London: V. Gollancz.

Baghramian, M. and Coliva, A.: forthcoming, Relativism, Routledge, London.

Baker, C. and Robson, J.: 2017, An absolutist theory of faultless disagreement in aesthetics, Pacific Philosophical Quarterly 98(3).

Batens, D.: 1990, Against global paraconsistency, Studies in East European Thought 39(3-4), 209-229.

Beall, J.: 2013, A simple approach towards recapturing consistent theories in paraconsistent settings, Review of Symbolic Logic 6(4), 755-764.

Beall, J. C.: 2006, Modelling the 'ordinary view', in P. Greenough and M. Lynch (eds), Truth and Relativism, Clarendon Press, pp. 61-76.

Beall, J. C.: 2009, Spandrels of Truth, Oxford University Press, Oxford, UK.

Beall, J. and Ripley, D.: 2004, Analetheism and dialetheism, Analysis 64(281), 30-35.

Berto, F.: 2008, Adynaton and material exclusion, Australasian Journal of Philosophy 86(2), 165-190.

Coliva, A.: 2009, I modi del relativismo, Laterza, Roma-Bari.

Coliva, A. and Moruzzi, S.: 2014a, Basic disagreement, basic contextualism and basic relativism, Iride $\mathbf{2 7}(2), 537-554$.

Coliva, A. and Moruzzi, S.: 2014b, Faultless disagreement and the equal validity paradox, in S. Caputo, F. Bacchini and M. Dell'Utri (eds), New Frontiers in Truth, Cambridge Scholars Publishing, Newcastle upon Tyne. 
de Sa, D. L.: 2015, Expressing disagreement: A presuppositional indexical contextualist relativist account, Erkenntnis 80(1), 153-165.

Dummett, M.: 1959, Truth, Proceedings of the Aristotelian Society 59. reprinted with a post-scriptum in Dummett (1978) p.1-24.

Dummett, M.: 1978, Truth and Others Enigmas, Duckworth.

Eklund, M.: 2010, Vagueness and second-level indeterminacy, in R. Dietz and S. Moruzzi (eds), Cuts and Clouds: Vaguenesss, its Nature and its Logic, Oxford University Press.

Ferrari, F.: 2016a, Disagreement about taste and alethic suberogation, The Philosophical Quarterly 66(264), 516-535.

URL: http://pq.oxfordjournals.org/content/66/264/516.abstract

Ferrari, F.: 2016b, Relativism, faultlessness and parity: Why we should be pluralists about truths normative function, Argumenta 2(1), 77-94.

Ferrari, F. and Wright, C.: 2017, Talking with vultures, Mind 126(503), 911936.

URL: + http://dx.doi.org/10.1093/mind/fzw066

Grim, P.: 2004, What is a contradiction?, in G. Priest, J. Beall and B. P. Armour-Garb (eds), The Law of Non-Contradiction : New Philosophical Essays, Oxford University Press, pp. 49-72.

Huvenes, T. T.: 2012, Varieties of disagreement and predicates of taste, Australasian Journal of Philosophy 90(1), 167-181.

Huvenes, T. T.: 2014, Disagreement without error, Erkenntnis 79(1), 143-154.

Iacona, A.: 2007, Faultless or disagreement, in M. Kölbel and M. GarcíaCarpintero (eds), Relative Truth, Oxford University Press. 
Kabay, P.: 2010, On the Plenitude of Truth: A Defense of Trivialism, Lambert Academic Publishing., Saarbrücken.

Kelly, T.: 2005, The epistemic significance of disagreement, in J. Hawthorne and T. Gendler (eds), Oxford Studies in Epistemology, Volume 1, Oxford University Press, pp. 167-196.

Kölbel, M.: 2003, Faultless Disagreement, Proceedings of the Aristotelian Society 54(1), 53-73.

Kölbel, M.: 2004, Indexical relativism versus genuine relativism, International Journal of Philosophical Studies pp. 297-313.

Lasersohn, P.: 2005, Context Dependence, Disagreement, and Predicates of Personal Taste, Linguisticis and Philosophy 28(6), 643-686.

Lasersohn, P.: 2013, Non-world indices and assessment-sensitivity, Inquiry : An Interdisciplinary Journal of Philosophy 56(2-3), 122-148.

Lynch, M. P.: 2009, Truth as One and Many, Oxford University Press.

MacFarlane, J.: 2014, Assessment Sensitivity: Relative Truth and Its Applications, Oxford University Press, Oxford.

Mares, E. D.: 2004, Semantic dialetheism, in G. Priest, J. C. Beall and B. Armour-Garb (eds), The Law of Non-Contradiction, Clarendon Press.

Marques, T.: 2014, Relative correctness, Philosophical Studies 167(2), 361-373. URL: $h t t p: / / d x . d o i . o r g / 10.1007 / s 11098-013-0100-3$

Moruzzi, S.: in corso di pubblicazione, Assertion, belief and disagreement: A problem for truth-relativism, in M. Kölbel and M. García-Carpintero (eds), Relative Truth, Oxford University Press.

Murzi, J. and Carrara, M.: 2014, Denial and disagreement, Topoi 34(1), 109119. 
Parsons, T.: 1984, Assertion, denial, and the liar paradox, Journal of Philosophical Logic 13(2), 137-152.

Parsons, T.: 1990, True contradictions, Canadian Journal of Philosophy 20(3), 335-353.

Pedersen, N.: n.d., On moderate pluralism about truth and logic: truth and logic as one, quasi-truth and quasi-logic as many.

Pedersen, N. J. L. L.: 2014, Pluralism x 3: Truth, logic, metaphysics, Erkenntnis $79(2), 259-277$.

Pedersen, N. J. L. L. and Wright, C. D.: 2013, Truth and Pluralism: Current Debates, Oxford University Press.

Plebani, M.: 2015, Could everything be true? probably not, Philosophia 43(2), 499-504.

Priest, G.: 1989, Reductio ad absurdum et modus tollendo ponens, in G. Priest, R. Routley and J. Norman (eds), Paraconsistent Logic. Essays on the Inconsistent, Philosophia Verlag, München, pp. 613-26.

Priest, G.: 1998a, To be and not to be - that is the answer. on aristotle on the law of non-contradiction, Logical Analysis and History of Philosophy 1.

Priest, G.: 1998b, What is so bad about contradictions?, Journal of Philosophy 95(8), 410-426.

Priest, G.: 2000, Could everything be true?, Australasian Journal of Philosophy 78(2), 189-195.

Priest, G.: 2005, Doubt Truth to Be a Liar, Oxford University Press.

Priest, G.: 2006, In Contradiction: A Study of the Transconsistent, Oxford University Press. 
Raffman, D.: 2016, Relativism, retraction, and evidence, Philosophy and Phenomenological Research 92(1), 171-178.

Richard, M.: 2008, When Truth Gives Out, Oxford University Press UK.

Ripley, D.: 2015, Embedding denial, in C. Caret and O. Hjortland (eds), Foundations of Logical Consequence, Oxford University Press, pp. 289-309.

Schafer, K.: 2011, Faultless disagreement and aesthetic realism, Philosophy and Phenomenological Research 82(2), 265-286.

Schiffer, S.: 2003, The Things We Mean, Oxford University Press, Oxford.

Schroeder, M. A.: 2008, Being For: Evaluating the Semantic Program of Expressivism, Oxford University Press.

Stanley, J.: 2016, On a case for truthrelativism, Philosophy and Phenomenological Research 92(1), 179-188.

Sundell, T.: 2011, Disagreements about taste, Philosophical Studies 155(2), 267-288.

Woods, J.: forthcoming, The Frege-Geach problem, in D. Plunkett and T. McPherson (eds), The Routledge Handbook of Metaethics, Routledge.

Wright, C.: 2007, Relativism about Truth Itself: further thoughts about the Very Idea, in M. Kölbel and M. García-Carpintero (eds), Relative Truth, Oxford University Press.

Wright, C.: 2012, Replies part iii: Truth, objectivity, realism and relativism, Mind, Meaning and Knowledge: Themes from the Philosophy of Crispin Wright, Oxford University Press., Oxford, pp. 418-50.

Wright, C.: 2016, Assessmentsensitivity: The manifestation challenge, Philosophy and Phenomenological Research 92(1), 189-196. 
Wright, C. J. G.: 2001, On being in a quandary. relativism vagueness logical revisionism, Mind 110(437), 45-97.

Wyatt, J.: 2013, Domains, plural truth, and mixed atomic propositions, Philosophical Studies 166(1), 225-236.

Wyatt, J.: forthcoming, Absolutely tasty: an examination of predicates of personal taste and faultless disagreement, Inquiry . 